\title{
SOBERANIA POPULAR, INSTRUMENTOS DEMOCRÁTICOS E A CONSTITUIÇÃO VIA FACEBOOK
}

POPULAR SOVEREIGNTY, DEMOCRATIC INSTRUMENTS AND THE CONSTITUTION VIA FACEBOOK

Helen Corrêa Solis Neves ${ }^{1}$ Laura Alves Araújo²

ISSUE DOI: $10.21207 / 1983.4225 .408$

\section{RESUMO}

O presente texto objetivo analisar a Constituinte islandesa de 2011 através da observação do momento político-social que a consolidou e de alguns aspectos de sua elaboração assentados no conceito de Soberania Popular, nos instrumentos de democracia semidireta e Poder Constituinte. Para a análise, foram utilizados artigos científicos e jornais que abordaram o tema, bem como doutrinas referentes à Ciência Política e Teoria Geral do Estado. Foram observadas as manifestações populares que levaram à elaboração da nova Constituição e a outros impactos no país, avistando o indício da soberania e seus desdobramentos. Além disso, as características intrínsecas do Poder Constituinte puderam ser distinguidas à luz das peculiaridades do

\footnotetext{
${ }^{1}$ Mestre em Direitos Humanos pela Universidade Católica de Brasília-UCB, graduada em Direito pela Universidade Federal de Uberlândia, Professora de Direito Constitucional do Centro Universitário de Patos de Minas - UNIPAM e do Centro Universitário do Triângulo - UNITRI, coordenadora do Grupo de Pesquisa JUHIS - Direito e História / CNPQ.

${ }^{2}$ Discente do Curso de Direito do Centro Universitário de Patos de Minas - MG (UNIPAM) e Pesquisadora do JUHIS - Grupo de Estudos e Pesquisas em Direito e História UNI$\mathrm{PAM} / \mathrm{CNPQ}$.
} 
processo islandês e delimitou-se a possibilidade de, no caso analisado, o referendo se desdobrar em veto popular - dois importantes instrumentos de democracia semidireta que também foram observados.

Palavras chave: Constituição da Islândia. Democracia Semidireta. Veto popular. Constituição via facebook.

\section{ABSTRACT}

This text aims to analyze the Icelandic Constitution of 2011 through observation of the social-political moment it provided and some aspects of it's preparation sitting on the concept of Popular Sovereignty, instruments of semi-direct democracy and Constituent Power. For the analysis were used scientific articles and papers that addressed the topic as well as doctrines related to political science and general theory of the State. Observed the demonstrations that led to the drafting of the new Constitution and other impacts in the country, noticing the sign of sovereignty and its ramifications. In addition, the intrinsic characteristics of the Constituent Power can be distinguished in view of the peculiarities of the Icelandic process and the possibility, in the case defined, the referendum test unfold in popular veto-two important instruments of semi-direct democracy which also were observed.

Keywords: Constitution of Iceland. Semi-direct Democracy. Popular veto. Constitution by facebook.

\section{INTRODUÇÃO}

A falência do Banco Lehman Brothers nos Estados Unidos provocou, em novembro de 2008, uma fragilidade econômica que abalou o mundo, ou pelo menos os países que aderiam ao sistema capitalista de mercado. A Islândia, país nórdico insular europeu, abandonaria o Welfare State e acabaria aderindo à política neoliberal, guiada pelos novos capitalistas do país. Em decorrência da crise, a Islândia imergiu também em um desequilíbrio político-social internamente. A população não estava mais satisfeita com os mandos e desmandos da política neoliberal e se mostrava preocupada com as dívidas que o país contraía junto ao Fundo Monetário Interna- 
cional. Manifestações populares e participações via referendo não só levaram à recuperação econômica islandesa, mas também à elaboração de uma nova Constituição com características singulares.

A abordagem dos precedentes da Constituinte e seus desdobramentos será fundamentada sob aspectos da soberania popular, no que se refere à participação do povo nos processos analisados, principalmente pela internet e redes sociais; da democracia semidireta, relativo ao referendo e veto populares, suas características e convergências; do Poder Constituinte, no tocante aos seus aspectos e manifestações na Assembleia islandesa.

Para tanto, foram utilizadas doutrinas brasileiras tradicionais que tratam dos temas concernentes à Ciência Política e Teoria Geral do Estado, além de monografias das áreas de Economia, no tocante à crise de 2008; e Direito, referente ao caso islandês e aos tópicos tratados no trabalho. Ainda, posto que a Constituinte ganhou pouca notoriedade no Brasil, puderam ser analisados alguns noticiários e editoriais que expunham o tema e que serviram de base para entender como a mídia lidava com o assunto.

A realização do trabalho justifica-se, primeiramente pela (pouca) repercussão do evento islandês e pelo intuito de vislumbrar as características que desinteressaram a grande mídia - entende-se que o ímpeto revolucionário do povo foi um dos principais fatores. Ademais, o recorte temático que caracterizava o evento: "Constituição via facebook e twitter", e a investigação do processo à luz do que a doutrina estabelece acerca do Poder Constituinte. E ainda, os mecanismos utilizados pela população islandesa para pressionar o governo e deixar transparecer suas vontades, sendo o referendo o principal.

\section{HISTÓRIA DA CRISE NA ISLÂNDIA}

Verifica-se no decorrer da história a eclosão de movimentos sociais e rupturas políticas quando há instabilidade econômica e, não raro, como causadores da mesma. Numa concepção marxista, o homem enquanto ser social, molda sua consciência e suas ideias tornam-se uma força material quando absorvida pelas massas, essa força é o motor da história manifesta na luta de classes. A convulsão política na Islândia emergiu exatamente de uma fragilidade econômica - crise de 2008 -, que culminou 
numa ação ordenada do povo e determinou diversas mudanças no país, processo que será aqui analisado.

O fim da URSS e a queda do Muro de Berlim marcaram o contexto econômico mundial representando o triunfo do capitalismo frente às tentativas de socialismo. Passou-se a confiar, pós-1990, no mercado livre e nos mecanismos de preço. O neoliberalismo aniquilaria o Estado Providência e, em pouco tempo, até países pequenos e estáveis como a Islândia abandonariam o Welfare State - estado de bem estar social - e imergiriam na política neoliberal.

Aliado a isto, na Islândia, via-se desde o início da década de 1990 a ascensão de um partido conservador e de direita, o Partido da Independência. Em pouco tempo, a pesca, principal atividade econômica do país insular, foi privatizada via criação de um sistema de cota baseado no histórico de produção de cada pescador. O Individual Transferrable Quota (ITQ) funcionaria como um bem alienável através do qual seria possível fazer transações e contrair empréstimos. Havia, portanto, estímulo migratório para o setor financeiro, e foi o que aconteceu.

As pessoas venderam suas quotas e mudaram seus ganhos para o sistema financeiro - ou setor virtual da economia. Enquanto isso, consecutivos governos neoliberais foram reduzindo impostos, soltando a regulamentação bancária e privatizando setores de telefonia, energia e, em 2000, o sistema bancário. [...] Agora a corrupção era endêmica, dobrar as regras havia se tornado a ordem do dia; partidos políticos distribuíam instituições inteiras - nomeadamente os bancos - para adeptos poderosos, enquanto, ao mesmo tempo, relaxava regulamentos sobre tudo, incluindo os bancos e o meio ambiente. A situação ficou fora de controle. $^{3}$

A privatização dos três maiores bancos islandeses, Glitnir, Landsbanki e Kaupthing, criou novas oportunidades ao empresariado, mas

\footnotetext{
${ }^{3}$ PALSSON, G.; DURREMBERGER, E. P. Gambling Debt: Iceland's rise and fall in the global economy. Boulder: University Press of Colorado, 2014. Disponível em: <http://www.upcolorado.com/excerpts/9781607323358.pdf >. Acesso em: 07 jul. 2016. p. 16.
} 
o sistema não duraria muito tempo. O ciclo pós-1980, segundo Palley, é embasado em "booms" financeiros nos quais o endividamento é suportado pela fácil concessão de crédito. ${ }^{4}$ Assim, a crise financeira de 2008 não fugiria do standart. Com o aval da especulação, via desregulamentação da economia, o sistema baseado nas supbrimes - créditos de risco, hipotecas de alto risco - desmoronou dando seu primeiro indício com a falência de um dos maiores bancos dos Estados Unidos, o Lehman Brothers. ${ }^{5}$

Sem credibilidade, o banco estadunidense não obteve ajuda nem do governo. Assim, fez com que as bolsas mundiais perdessem quatro trilhões de dólares só na semana em que havia declarado falência (15/09/2008). Os bancos islandeses não estavam imunes à crise. Além de não possuírem reservas para pagar os empréstimos contraídos e estarem cheios de débitos, já não contavam mais com os fundos que emprestavam dinheiro e que, naquele momento, apostavam contra a economia islandesa. ${ }^{6}$

Em decorrência da falta de empréstimos e de capital, estatizaram os bancos e a bolsa de valores foi fechada. O Primeiro Ministro Geir H. Haarde aprovou a Lei de Emergência que traçava os caminhos a serem percorridos para enfrentar a crise. Nada benéfica aos credores internacionais, a lei dava prioridade de pagamento aos correntistas. Na tentativa de garantir os investimentos dos britânicos em bancos islandeses, o Reino Unido colocou o Banco Central Islandês na lista de organizações terroristas - junto à Al Qaeda e os talibãs - com o objetivo de congelar os bens islandeses em seu território. ${ }^{7}$

Tendo em vista a situação caótica, a Islândia recorreu a um empréstimo de dois bilhões de dólares do Fundo Monetário Internacional. Como de praxe, toda ajuda concedida pelo FMI às economias vem acompanhada de uma exigência de austeridade. Com a Islândia não foi diferente. Mas em nítida e ferrenha oposição às imposições do FMI, a partir de 2009,

\footnotetext{
${ }^{4}$ PALLEY apud PACHECO. Análise comparativa entre as crises financeiras de 1929 e 2008: um arcabouço pós-keynesiano. p. 45-58. (Monografia). Universidade Federal de Santa Catarina, Centro Socio-Econômico, 2013.

${ }^{5}$ SERENATO, Maurício Wosniaki. Evento, poder constituinte e democracia: uma análise a partir do caso islandês. UFPR, 2015. p.53-54.

${ }^{6}$ Ibidem. p. 52.

${ }^{7}$ Ibidem. p. 53.
} 
a frente do Alpingi (Parlamento Islandês) vivia tomada pelo povo em protesto. Em 26 de janeiro, o Primeiro Ministro renunciou e com ele se foi toda a lógica empreendida pelo governo. ${ }^{8} 9$

Antecipadas as eleições para dois anos antes do previsto, pela primeira vez desde 1944, quando a Islândia se separou da Dinamarca, a esquerda obtém maioria absoluta no Alpingi. Ocupando o cargo de Ministro das Finanças, Steingrímur J. Sigfússon, líder da Esquerda Verde, era a luz no fim do túnel. Por pouco tempo.

[...] coube a um governo de esquerda implementar o primeiro programa do FMI num país do Primeiro Mundo desde a década de 70 - e o gabinete que substituiu o de Geir Haarde não só o implementou, como mereceu efusivos elogios. No derradeiro relatório de avaliação do programa, publicado pelo Fundo em agosto de 2011, lê-se: "Exemplar". ${ }^{10}$

Como se não bastasse a decepção para com o governo de esquerda que se rendera às tentações do mercado, os islandeses se deparavam, exasperados, com o caso Icesave ${ }^{11}$. No episódio do crash, o Icesave foi dividido em dois, um banco doméstico, sendo administrado pelo Estado, e um estrangeiro que seria liquidado. Holanda e Grã-Bretanha, insatisfeitas, dispuseram-se, visto sua influência, principalmente da segunda, no FMI, a barrar auxílios que seriam dados à Islândia. Pressionado, o governo propôs o pagamento da dívida após 2017, lei que fora aprovada em 30 de dezembro de 2009 pelo Parlamento. ${ }^{12}$

\footnotetext{
${ }^{8}$ SERENATO, Maurício Wosniaki. Evento, poder constituinte e democracia: uma análise a partir do caso islandês. UFPR, 2015. p. 55.

${ }^{9}$ Entende-se por lógica o sistema neoliberal articulado e executado pelo Partido da Independência.

${ }^{10}$ SALLES, João Moreira. Manifestações derrubaram governo e prenderam banqueiros no início da crise. Revista Caros Amigos Online. Disponível em: http://www.carosamigos.com.br/index.php/artigos-e-debates/3262-islandia-do-ardor-revolucionario-a-descrenca. Acesso em: 27 jul. 2016.

${ }^{11}$ Banco online gerenciado pelo Landsbanki que captava correntistas fora da Islândia, principalmente na Holanda e Grã-Bretanha.

${ }^{12}$ SERENATO, Maurício Wosniaki. Evento, poder constituinte e democracia: uma análise a partir do caso islandês. Monografia graduação, UFPR, 2015. p. 63-68.
} 
Embora o Presidente da República não exerça influência significativa no Legislativo do país, visto que a Islândia é uma República Parlamentarista $^{13}$, para que um projeto de lei entre em vigor, após sanção no Alpingi, deve ser assinado pelo Presidente ${ }^{14}$. Eis que a Islândia, segundo Paul Krugman - economista americano - fez zag quando todos diziam que ela deveria fazer zig. ${ }^{15}$

Para que a lei de pagamento das dívidas do Icesave fosse aprovada, portanto, Ólafur Ragnar Grímsson, Presidente da República, deveria assiná-la. Organizada, a população foi para as ruas protestar e o Presidente, acuado, não assinou. Conforme o artigo que determina o procedimento, se em duas semanas não houver posicionamento, os eleitores devem "fazer o papel do presidente", entenda-se: votar para aprovação ou rejeição da lei.

Dois meses depois, 6 de março de 2010, 93\% dos eleitores rejeitaram, sendo apenas $2 \%$ favoráveis ao pagamento da dívida. Já no início de 2011, o Parlamento alegou que sabia o valor da massa falida podendo, portanto, a dívida ser paga sem sacrifício do Tesouro e fez uma nova proposta. Rejeitada novamente, agora por $60 \%$ dos eleitores. ${ }^{16}$ Houve, pois, duas consultas populares sobre o mesmo tema em menos de um ano. Disse o professor de história da Universidade da Islândia, Gudmundur Jónsson, que a segunda vez em que a aprovação foi submetida aos eleitores não passou de manobra do Presidente da República.

A escolha do presidente foi interpretar o humor da nação dizendo que havia uma cisão entre o Parlamento e a sociedade. Não havia. Uns dias antes

${ }^{13}$ Constitution of The Republic of Iceland, 1944. Article 1: Iceland is a Republic with a parliamentary government.

${ }^{14}$ Article 26: If Althingi has passed a bill, it shall be submitted to the President of the Republic for confirmation not later than two weeks after it has been passed. Such confirmation gives it the force of law. If the President rejects a bill, it shall nevertheless become valid but shall, as soon as circumstances permit, be submitted to a vote by secret ballot of all those eligible to vote, for approval or rejection. The law shall become void if rejected, but otherwise retains its force. Constitution of The Republic of Iceland, 1944. Article 1: Iceland is a Republic with a parliamentary government.

${ }^{15}$ SALLES, João Moreira. Manifestações derrubaram governo e prenderam banqueiros no início da crise. Revista Caros Amigos Online. 2012. Disponível em: http://www.carosamigos.com.br/index.php/artigos-e-debates/3262-islandia-do-ardor-revolucionario-adescrenca. Acesso em: 27 jul. 2016.

${ }^{16}$ SERENATO, Maurício Wosniaki. Evento, poder constituinte e democracia: uma análise a partir do caso islandês. Monografia graduação, UFPR, 2015. p. 65-66. 
do segundo referendo, a maioria dos islandeses era favorável ao pagamento. Ele cruzou uma fronteira constitucional ao não respeitar o que o Parlamento havia decidido." [...] Pegue um táxi e pergunte ao motorista: 'Quer pagar uma dívida para estrangeiros?' É ridículo submeter uma pergunta dessas a referendo. O presidente é um demagogo. ${ }^{17}$

Manobrista ou não, fato é que Ólafur Ragnar ouviu, entendeu e se rendeu, ou melhor, acolheu o furor do povo islandês. Embora o Ministro da Economia tenha argumentado que os números davam a evidência de que os custos do segundo acordo eram insignificantes, a Islândia optou por "dar o calote". Em entrevista à revista Carta Capital em 2015, o Presidente entregou a estratégia islandesa para a recuperação:

Não seguiu a receita tradicional oferecida pelas instituições financeiras. Não concordamos que as pessoas comuns deveriam pagar a dívida dos bancos falidos. Não introduzimos medidas de austeridade. Tentamos proteger os pobres, os serviços de saúde, o sistema educacional. Adotamos uma carga tributária justa, onde os ricos foram solicitados a contribuir mais. Desvalorizamos a moeda para instilar mais competitividade nos setores de exportação. E, através da minha decisão no referendo, demos maior importância à democracia do que aos mercados financeiros. - Ólafur Ragnar Grímsson. ${ }^{18}$

\footnotetext{
${ }^{17}$ SALLES, João Moreira. Manifestações derrubaram governo e prenderam banqueiros no início da crise. Revista Caros Amigos Online. 2012. Disponível em: http://www.carosamigos.com.br/index.php/artigos-e-debates/3262-islandia-do-ardor-revolucionario-adescrenca. Acesso em: 27 jul. 2016.

${ }^{18}$ THOMAZ, Paula. A Islândia prepara nova constituição. Via Facebook. Revista Carta Capital Online, 7 de julho de 2011. Disponível em: <http//www.cartacapital.com.br/internacional/a-islandia-prepara-nova-constituicao-via-facebook> Acesso em: 07 jul. 2016.
} 
Com seu ímpeto insurgente notável, o povo islandês quis mostrar que aprendeu muito com seu episódio político-econômico-social e, principalmente, com sua crise de representação política - sentida após o deslize do Ministro esquerdista que caluniava o FMI, mas acabou sendo seu fiel adepto. Para isso, a Islândia precisava fugir do molde conservador do Parlamento. A pressão nas ruas foi tanta que o premiêr Steingrímur convocou uma Assembleia Nacional Constituinte. Seria feita uma nova Constituição, não mais copiada, como a do pós independência ${ }^{19}$, mas pelas mãos do povo.

O Parlamento então se dispôs a escolher responsáveis pela preparação laboral da Assembleia Constituinte, um Comitê Constitucional, formado por setes pessoas especialistas em direito, ciência e literatura via indicação parlamentar. Duramente criticado pela população, visto seu aspecto elitizado, o Comitê sequer se reuniu. Em substituição ao Comitê foi criado um Fórum Nacional composto por 950 cidadãos escolhidos aleatoriamente e tomando o cuidado de garantir as igualdades de gênero e regional - devendo ser representados todos os territórios e com igual número de homens e mulheres. ${ }^{20}$

Como delineado pelo Fórum, a formação da Assembleia Constituinte se daria via eleição, com algumas peculiaridades. Desde que obtivesse indicação de, no mínimo, trinta outros cidadãos, qualquer um poderia se candidatar. Naquela ocasião, 522 pessoas concorriam às eleições da Assembleia. Faz-se necessário enfatizar que não houve participação partidária no processo, embora não houvesse restrição acerca da candidatura de membros de partidos políticos. Ainda, é importante salientar que, mesmo não havendo impedimento à participação dos partidos políticos, sendo a Constituição do povo contrária à elite política, eles não fizeram qualquer esforço para incentivar as pessoas a votarem. ${ }^{21}$

Divididos em três grupos, os membros da Assembleia Constituinte cuidaram do esboço da Constituição. Tendo em vista a aspiração de ampla participação popular, as reuniões da Assembleia foram transmitidas ao vivo pela internet e as deliberações eram postadas diariamente no site. Não obstante, os constituintes solicitaram a contribuição do povo islandês que, por meio de redes sociais como Facebook e Twitter e através do site

${ }^{19}$ A Constituição da Islândia de 1944 era basicamente uma cópia da Constituição da Dinamarca, país do qual ficou independente.

${ }^{20}$ SERENATO, Maurício Wosniaki. Evento, poder constituinte e democracia: uma análise a partir do caso islandês. Monografia graduação, UFPR, 2015. p. 85-86.

${ }^{21}$ Ibidem. p. 92. 
do Conselho, enviaram comentários (totalizando 3.600) e sugestões formais (370). ${ }^{22}$

Além de especial atenção aos Direitos Humanos no texto Constitucional, a Constituinte islandesa deu ênfase aos direitos que tangem à natureza, colocando os recursos naturais, por exemplo, como propriedade coletiva e eterna do povo islandês, proibindo assim sua apropriação privada. Ademais, foram inseridos mecanismos de participação popular como o artigo 65 que previu que $10 \%$ dos votantes poderiam exigir um referendo nacional em relação a qualquer lei aprovada no Parlamento. ${ }^{23}$

Em suma, nesse ponto, a elaboração da Carta já havia passado por duas fases (à exceção da indicação parlamentar que foi recusada pelo povo): a primeira foi a reunião de 950 pessoas em um Fórum para delimitar como seriam a escolha e a atuação da Assembleia Constituinte, e a segunda foi a eleição da Assembleia propriamente dita ( 25 pessoas). Para que a Constituição entrasse em vigor, segundo os ditames do Fórum, era preciso que fosse submetida a referendo popular. Embora aprovada por $70 \%$ dos eleitores, a Constituição trilharia um caminho não previsto pelos seus organizadores (Comitê), tampouco pelos constituintes.

Com o intuito de anular as intenções em relação à nova Carta, começaram a surgir contestações acerca da formação da Assembleia Constituinte. Na ocasião em que foram eleitos seus 25 integrantes, houve reclamações acerca da contagem e do tamanho das cabines eleitorais por indivíduos com ligação com o Partido da Independência, nitidamente contrário ao processo. Contudo, a Suprema Corte decidiu por 6 a 3 anular as eleições (escolha dos membros da Assembleia Constituinte) para a Assembleia. Maurício Wosniaki Serenato observa:

O professor islandês (Thorvaldur) não deixa de notar que cinco dos seis juízes que votaram pela anulação da eleição tinham alguma forma de ligação com o Partido da Independência. Ainda, dos 6 juízes que votaram pela anulação da votação, quatro já haviam declarado publicamente serem contrários a propriedade nacional dos recursos nacionais, que configurava evidente contra-ofensiva ao modelo de

\footnotetext{
${ }^{22}$ SERENATO, Maurício Wosniaki. Evento, poder constituinte e democracia: uma análise a partir do caso islandês. Monografia graduação, UFPR, 2015. p. 96.

${ }^{23}$ Ibidem. p. 101.
} 
ITQs - gérmen da crise islandesa. [...] ainda assim, nenhum dos juízes da Suprema Corte se declarou impedido para o julgamento". ${ }^{24}$

Cercado de questionamentos por ter anulado a eleição para a Assembleia Constituinte feita pelo povo e, prevendo sua reação, o Parlamento decidiu que os 25 membros eleitos seriam indicados para compor a Assembleia (agora chamada de Conselho), os mesmos escolhidos pelo povo, só que indicados pelo parlamento. Assim, a aprovação da Constituição deveria passar pelas mãos dos parlamentares, que garantiram sua participação ao indicar os membros da Assembleia. Logo, a prerrogativa da indicação serviria exatamente para deixar a decisão final com o Parlamento. Discutido, portanto, pelos parlamentares e pela Comissão de Veneza, o projeto de Constituição não passou pela peneira. Os relatórios indicam, entre outros fatores, deficiência técnica e falta de esclarecimento de questões importantes para o país. O parlamento, pois, não adotou a nova Constituição. ${ }^{25}$

\section{ANÁLISE DO PROCESSO CONSTITUINTE À LUZ DA SOBERANIA POPULAR E PODER CONSTITUINTE}

A participação do povo foi determinante para a superação da crise financeira vivida pela Islândia. Como afirmou o Ministro da Economia em entrevista já citada, a receita para retomar o crescimento econômico embasou-se no privilégio dado à democracia em detrimento do mercado financeiro. Como resultado, o país insular não se contentaria somente com a superação, após experimentada a democracia de fato. $\mathrm{O}$ povo necessitava rever seus instrumentos democráticos e suas instituições, impulsionados também pelo conservadorismo do Parlamento que, por vezes, pareceu ser um entrave às suas vontades. Para isso, criaram uma nova Constituição, cujo processo será aqui brevemente analisado, assentado em dois conceitos: Soberania Popular e Poder Constituinte.

\footnotetext{
${ }^{24}$ SERENATO, Maurício Wosniaki. Evento, poder constituinte e democracia: uma análise a partir do caso islandês. Monografia graduação, UFPR, 2015. p.95.

${ }^{25}$ Ibidem. p. 98-103.
} 
Um dos filósofos que melhor descreve o conceito de Soberania Popular é Jean-Jacques Rousseau.

E o que é, segundo Rousseau, a soberania? Não é outra coisa senão o exercício da vontade geral, sendo esta a vontade do corpo do povo e tendendo sempre ao bem comum. Do contrário, "não passa de uma vontade particular ou de um ato de magistratura, quando muito de um decreto". (Rousseau, 1978b, p. 44). Desse modo, a soberania não pode ser alienada e, tampouco, dividida. ${ }^{26}$

Não há sociedade para Rousseau se os interesses forem esparsos e não constituírem o que ele chama de vontade geral. Para ele, se o ser humano se restringir a obedecer ordens e leis ele perde sua característica, já que estaria presente um senhor que governa, não um soberano. Soberania está diretamente ligada ao exercício da vontade geral, que não é a vontade de um só, mas a vontade de um corpo político. O principal ponto que merece atenção é que a vontade geral não é algo diverso da vontade individual, nem igual, nem estranho. Isso significa que a vontade geral é a forma como se dirige o Estado, segundo a soberania do povo que a exerce, elaborando leis que visem ao bem comum. ${ }^{27}$

Deste modo, é possível entender toda a história acerca da Islândia, sua crise financeira e consequente recuperação através do conceito de Soberania Popular. Houve pressão contra o conservadorismo do Parlamento que gerou abertura, pelo Presidente da República, para referendar assuntos de interesse do povo, o que representa em partes a Soberania Popular, já que o povo não elaborou as leis, apenas as referendou. Não obstante, posteriormente, entende-se que o povo, exercendo a soberania, elaborou uma nova Constituição, criando leis em prol do bem comum, com objetivo de gerir-se pela vontade geral.

O conceito de soberania deixa suas marcas no preâmbulo da nova Constituição de 2011: "Nós, o povo da Islândia, queremos criar uma soci-

\footnotetext{
${ }^{26}$ ANTUNES, Vanderlei Lemos. O Conceito de Soberania em Jean-Jacques Rousseau. p.4. Controvérsia. v.2, n.1, 2006. p. 70-77.

${ }^{27}$ Ibidem. p. 5-6.
} 
edade justa que ofereça as mesmas oportunidades a todos. Nossas diferentes origens são uma riqueza comum e, juntos, somos responsáveis pela herança de gerações". ${ }^{28}$

Em se tratando de Poder Constituinte, faz-se mister enfatizar que o fato de a Constituição islandesa ter sido elaborada online e com participação popular pelas redes sociais, só reforça e deixa mais visíveis as características do Poder Constituinte Originário Revolucionário.

Adotando a corrente positivista, em oposição à jusnaturalista, para a qual o poder constituinte possui limitações do direito natural, reconhece-se o Poder Constituinte como ilimitado juridicamente, sendo possível quebrar o conservadorismo parlamentar, como queriam os islandeses, e elaborar uma Constituição mais democrática e liberal (do ponto de vista social), e foi o que aconteceu. Além disto, ele é incondicionado, ou seja, a tomada de decisões não precisa se submeter a nenhuma força prefixada de manifestação, daí infere-se que não há problemas em a Constituição ter sido feita parcialmente pelo facebook, twitter entre outras redes sociais. ${ }^{29}$

Inicialmente foi criado um Fórum para traçar as diretrizes da elaboração da nova Carta. A Assembleia Constituinte eleita seguiu as determinações formais feitas pelo Fórum, em relação à quantidade de membros (igualdade por região e mesma quantidade de homens e mulheres, além da representação de grupos minoritários) e a disponibilização online. Por isso, é preciso deixar claro que a qualidade de incondicionado permanece, já que o Fórum, livremente, estabeleceu somente algumas diretrizes formais.

Outrossim, é possível entender como Soberania Popular, não só o caráter peculiar do Poder Constituinte, mas também as leis referendadas em relação ao pagamento ao FMI, que só foi possível através de dispositivo

\footnotetext{
${ }^{28}$ A Proposal for a New Constitution for The Republic of Iceland. Preamble: We, the people who inhabit Iceland, wish to create a just society where every person has equal opportunity. Our diverse origin enriches our society and together we are responsible for the heritage of generations, our country and its history, nature, language and culture.

Iceland is a free and sovereign state with freedom, equality, democracy and human rights as its cornerstones. The government shall endeavour to strengthen the welfare of the country's inhabitants, encourage their culture and respect the diversity of the life of the people, the country and its biosphere. We wish to promote harmony, security and happiness amongst us and coming generations. We are determined to work towards peace with other nations and respect for the earth and all mankind. In light thereof we set a new Constitution, the supreme law of the land that all must observe.

${ }^{29}$ LENZA, Pedro. Direito Constitucional Esquematizado. 18. ed. rev., atual e ampl. São Paulo: Saraiva, 2014. p. 214.
} 
constitucional que dava ao povo poder de sanção via referendo. Assim, o povo, soberanamente, decidiu sobre o pagamento de dívidas aos credores externos via instrumento da democracia semidireta. $\mathrm{O}$ referendo, neste caso, pode assumir a conotação de outro instrumento democrático, visto que cabia à população, já que o Presidente não se manifestou, vetar ou não a proposta. Seria o referendo, pois, uma possibilidade de veto popular?

\section{REFERENDO E VETO POPULAR: ESTUDO DOS INSTRUMENTOS DEMOCRÁTICOS DA CONSTITUIÇÃO ISLANDESA DE 1944}

Ao examinar o conceito de democracia, abandonando sua ideia utópica que remete mais ou menos ao que acontecia na Ágora (Grécia Antiga), verifica-se que, embora a sociedade não tenha experimentado nada que pareça àquela mencionada, deve-se partir de uma ideia de governo do povo e para o povo. Assim, foge-se da noções de concentração de poderes em uma só figura, absolutismo; ou em figuras seletas, aristocracia - leia-se seletividade por questões econômicas.

Nas democracias, o povo é o titular do poder soberano e, ainda que não o exerça diretamente, elege seus representantes. O exercício da democracia está ligado ao da vontade (da maioria) de seus titulares, não obstante ela garanta e proteja os direitos fundamentais dos indivíduos e da minoria. Não deixa de ser, portanto, um instrumento que garante a igualdade e liberdade humanas.

A democracia semidireta é uma "junção" de outros dois modelos: democracia direta e indireta. A primeira é aquela que era exercida na Grécia Antiga, em que o povo tomava as decisões do Estado diretamente. A segunda é aquela cujas decisões são tomadas pelos representantes eleitos. Para democracia semidireta há de se considerar que ela se molda no propósito de que tudo deve se passar como se o povo governasse de fato. $\mathrm{O}$ titular do poder soberano não só elege, mas também participa do processo legislativo, ocorrendo, pois, participação jurídica além da política. ${ }^{30}$

Observando o processo que culminou na elaboração de uma nova Constituição na Islândia, vê-se que o povo contava com, pelo menos, um

\footnotetext{
${ }^{30}$ BONAVIDES, Paulo. Curso de Direito Constitucional. 10 ed. rev, atual e ampl. São Paulo: Malheiros Editores, 2000. p. 296.
} 
instrumento de democracia semidireta que o fazia participante na sanção das leis, o referendo. Neste caso, de forma peculiar, o instituto é vinculado ao (não) exercício da aprovação das leis pelo Presidente da República, situação a ser analisada.

Na condição de República Parlamentarista, o Presidente da República é o Chefe de Estado, responsável pelas questões externas do país. Por sua vez, o Parlamento tem como Chefe de Governo o Primeiro Ministro. Mas, a experiência mostra que Parlamento e Presidente têm se organizado de formas diferentes, totalizando cinco combinações de exercício de função, uma verdadeira mistura de atribuições, segundo Darcy Azambuja. Aquela seguida pela Islândia é a que o Poder Executivo é exercido pelo Conselho de Ministros, cujos atos são promulgados pelo Presidente, que é politicamente responsável. ${ }^{31}$ Assim sendo, o Presidente participa do processo de feitura das leis. Mas, como é possível na Islândia, e se ele se abstiver?

Como dito anteriormente, segundo o artigo $26^{32}$ da Constituição da Islândia de 1944, para que uma lei seja aprovada sem a apreciação do Presidente da República, ela deve passar por referendo, o que vale também para emenda constitucional, artigo $79^{33}$. Isto é, se o Presidente não sancionar ou vetar, o povo os faz. Este tipo de referendo caracteriza-se como legislativo ou constitucional, segundo a matéria; obrigatório, segundo à natureza jurídica e segundo os efeitos, constitutivo. ${ }^{34}$

\footnotetext{
${ }^{31}$ AZAMBUJA, Darcy; CARRASCO, Alexandre de Oliveira Torres. Teoria Geral do Estado. 2. ed. São Paulo: Globo, 2008. p. 334.

${ }^{32}$ Constitution of The Republic of Iceland, 1944. Article 26: If Althingi has passed a bill, it shall be submitted to the President of the Republic for confirmation not later than two weeks after it has been passed. Such confirmation gives it the force of law. If the President rejects a bill, it shall nevertheless become valid but shall, as soon as circumstances permit, be submitted to a vote by secret ballot of all those eligible to vote, for approval or rejection. The law shall become void if rejected, but otherwise retains its force.

${ }^{33}$ Idem. Article 79: Proposals to amend or supplement this Constitution may be introduced at regular as well as extraordinary sessions of Althingi. If the proposal is adopted, Althingi shall immediately be dissolved and a general election held. If Althingi then passes the resolution unchanged, it shall be confirmed by the President of the Republic and come into force as constitutional law.
}

If Althingi passes an amendment to the status of the Church under Article 62, it shall be submitted to a vote for approval or rejection by secret ballot of all those eligible to vote.

${ }^{34}$ BONAVIDES, Paulo. Curso de Direito Constitucional. 10 ed. rev, atual e ampl. São Paulo: Malheiros Editores, 2000. p. 303-304. 
Ao afirmar que o referendo pode ser legislativo e constitucional, diz-se que tanto em processos legislativos ordinários quanto em alterações à Constituição, a lei passará por referendo caso o Presidente se abstenha da sanção ou veto.

O referendo é obrigatório, neste caso, porque ele advém necessariamente de disposto constitucional, não dependendo de determinação de qualquer órgão ou corpo eleitoral para requerer a consulta.

O referendo é constitutivo já que objetiva-se a criação de nova lei. Como ensina Paulo Bonavides: "Com o referendum constitutivo, a norma jurídica entra a existir; com o referendum ab-rogativo, a norma vigente expira". ${ }^{35}$ Assim, a modalidade prevista na Constituição é constitutiva, posto que é utilizada para a sanção ou veto de normas aprovadas no Parlamento (Althingi), portanto, que pretendem existir no ordenamento jurídico.

Ademais, observando o instrumento que dispõe a Constituição islandesa, nota-se a possibilidade de enxergá-lo, sob um ponto de vista específico, como veto popular. Para isto, faz-se mister precisar o raciocínio, já que ele se afasta de certo modo do que diz a doutrina. Admite-se aqui, portanto, a parte da doutrina que trata do referendo facultativo equiparadamente ao veto popular, representada por autores como Duverger e Santi Romano. $^{36}$

Assinalou o jurista italiano, Santi Romano, sobre o veto popular: "dentro de um determinado prazo, um certo número de cidadãos declara opor-se a uma lei deliberada pela Assembleia Legislativa", a decisão final sobre declaração ou rejeição cabe a eles. ${ }^{37}$

O objetivo é, portanto, sob a ótica apresentada acerca do veto popular, conseguir entender o referendo convocado na Islândia pelo Presidente Ólafur Ragnar também como uma possibilidade de veto popular. Ao considerar que, nas duas ocasiões em que a lei orçamentária foi submetida a referendo, ela foi rejeitada, é admissível enxergar o instrumento democrático também como referendo facultativo/veto popular.

\footnotetext{
${ }^{35}$ BONAVIDES, Paulo. Curso de Direito Constitucional. 10 ed. rev, atual e ampl. São Paulo: Malheiros Editores, 2000. p. 303-304.

${ }^{36}$ Ibidem. p. 316.

${ }^{37}$ GARCIA, Alexandre Navarro. Democracia semidireta: Referendo, plebiscito, iniciativa popular e legislação participativa. p.11.
} 
O veto popular, para Bonavides é " [...] a faculdade que permite ao povo manifestar-se contrário a uma medida ou lei, já devidamente elaborada pelos órgãos competentes, e em vias de ser posta em execução". ${ }^{38}$ Portanto, se a lei já foi devidamente elaborada, quer dizer que cumpriu todas as regras de elaboração (todo o trâmite) e depende de aplicação, já que está em vias de ser executada. Logo, o veto popular dar-se-á sobre leis que já existem no ordenamento jurídico, que já foram publicadas e estão em vias de produzir efeito. Já o referendo ocorre quando a medida a ser aplicada encontra-se pronta porém não vigente, o povo tem o poder de vetá-la ou sancioná-la, ou seja, ela ainda não existe no ordenamento jurídico.

A importância desse tipo de análise se dá na compreensão da abrangência e praticidade que ela denota. Ao entender que o que ocorreu na Islândia foi veto popular, admite-se que este pode ser admitido antes mesmo de a norma viger. Assim, nesta linha de raciocínio, o Parlamento não precisaria obedecer todo o trâmite para saber se a matéria da lei em elaboração é ou não aprovada pelo povo, já que o veto não precisaria ocorrer necessariamente na vigência da lei. Essa acepção dá mais espaço para a participação popular e, consequentemente, para transformações, o que nem sempre ocorre com o referendo.

Por mais entusiasmante que seja, o referendo, na sua interpretação geral, não mostrou ser um instrumento utilizado para fortes mudanças sociais, embora doutrinariamente houvesse temor de seu uso revolucionário. Autores chegaram a afirmar que, no fundo, o povo guarda um resquício de conservadorismo que não permite que ele o usufrua de forma abrupta ou revolucionária. ${ }^{39}$

Apesar disto, na Islândia, o uso do referendo - assim considerado pela Constituição - proporcionou, mesmo que indiretamente, uma mudança social singular, já que ela refletiu no processo constituinte iniciado posteriormente. Como já explanado, o Presidente Ólafur Ragnar, deixou que a questão orçamentária fosse submetida a referendo, em menos de um ano, por duas vezes. Mesmo trazendo legitimidade e participação social, poderia qualquer matéria ser referendada?

Justifica-se a pergunta pelo fato de Gudmundur Jónsson, historiador citado anteriormente, ter feito uma afirmação dizendo ser ridícula a

\footnotetext{
${ }^{38}$ BONAVIDES, Paulo. Curso de Direito Constitucional. 10 ed. rev, atual e ampl. São Paulo: Malheiros Editores, 2000. p. 380.

${ }^{39}$ Ibidem. p. 308-309.
} 
submissão da matéria, na segunda ocasião, a referendo. $\mathrm{O}$ historiador explica que a população já entendia que o pagamento da dívida ao FMI, naquele caso, seria benéfico ao país até para passar uma imagem de bons pagadores, e que a quantia seria insignificante aos cofres nacionais, posto que a Islândia já estava se recuperando da crise. No seu entendimento, o Presidente da República cruzou uma fronteira ao decidir não aprovar nem rejeitar a lei, deixando-a ir a referendo. O professor dá a entender, além disso, que a abordagem da pergunta foi pouco concreta, demagógica. Não cabe aqui fazer juízo de valor sobre a decisão do Presidente, nem mesmo acerca do resultado do referendo em questão. Mas, é possível encontrar fundamento no que o historiador explica, há limites ou, pelo menos, "recomendações teóricas" a respeito da matéria que deve conter ou não em um referendo. Darcy Azambuja coloca que, segundo Barthélemy, "o que se submete geralmente ao povo não são sutilezas de técnica legal, nem se lhe pede a elaboração de uma lei. A matéria do referendo é sempre, ou deve ser, uma questão concreta". ${ }^{40}$

As desvantagens do referendo, elenca Bonavides:

[...] desprestígio das câmaras legislativas, consequente à diminuição de seus poderes; índices espantosos de abstenção; [...] abusos de uma repetição frequente ao redor de questões mínimas, sem nenhuma importância, que acabariam provocando o enfado popular; afrouxamento da responsabilidade dos governantes (ao menor embaraço comodamente transfeririam para o povo o peso das decisões); o escancarar de portas à mais desenfreada demagogia; em suma, o dissídio essencial da instituição com o sistema representativo. ${ }^{41}$

O entendimento do historiador islandês vai de encontro às teorias, tanto porque o referendo foi repetido, quanto porque sua matéria era de discussão parlamentar, tendo em vista que contemplava objetos específicos orçamentários que definiriam o futuro do país, no sentido de ter que

${ }^{40}$ AZAMBUJA, Darcy; CARRASCO, Alexandre de Oliveira Torres. Teoria Geral do Estado. 2. ed. São Paulo: Globo, 2008. p. 257.

${ }^{41}$ BONAVIDES, Paulo. Curso de Direito Constitucional. 10 ed. rev, atual e ampl. São Paulo: Malheiros Editores, 2000. p. 307-308 
escolher se pagaria as dívidas ou ficaria inadimplente. Nota-se que a questão envolve uma participação da população em um momento decisivo, mas que pode ser apontada como equivocada pela forma como foi feita (referendada) e pelo momento político conturbado e carente de participação popular direta, leia-se passível de "manobra", como disse Gudmundur Jónsson.

Embora a doutrina "aconselhe" no que se refere às matérias do referendo, é possível enxergá-lo de um outro ângulo. O exercício do Poder Soberano pelos representantes do povo não anula sua titularidade, ou seja, o povo continua sendo titular do poder. Ainda assim há perguntas que não podem ser feitas?

Na verdade, não há nada que impeça, por exemplo, o Poder Constituinte Originário de estabelecer que todas as normas devem ser objeto de consulta popular direta, tampouco de os representantes invocarem o povo para consulta com frequência. Entretanto, consonante à doutrina citada, há o risco de a matéria do referendo não ser concreta o suficiente para ser facilmente compreensível ou de ser específica demais e de conteúdo não acessível. Além disso, as consultas frequentes podem afrouxar os poderes, principalmente o Judiciário, e até desestimular a população e/ou os detentores do monopólio da comunicação usarem de mecanismos para manipulá-la. Logo, é preciso, no mínimo, precisão ao delegar ao povo o poder de decidir questões específicas.

\section{CONSIDERAÇÕES FINAIS}

A presença do corpo político se fez evidente durante o processo aqui analisado, posto que vontades esparsas (vontade da minoria que detinha o poder econômico), foram rechaçadas pela soberania do povo que dirigiu o Estado, ou, pelo menos, traçou limites e caminhos para que esse Estado seguisse, visando ao bem comum. Um dos possíveis motivos para a singela repercussão que o caso teve, além do momento conturbado que não permitia dar atenção a todos que estavam em crise, é o significado da participação política do povo. A Islândia não se ateve somente a decidir minúcias via referendo ou a protestar em frente o Parlamento. O povo islandês, soberanamente, prontificou-se a elaborar uma nova Constituição a fim de quebrar definitivamente o conservadorismo dos governantes e a atender, de fato, os seus interesses. 
Embora a Constituição não tenha sido aprovada, segundo o historiador citado, por manobra do Parlamento, o processo denota uma organização ímpar do corpo político, tanto para a feitura da Carta quanto nas decisões via referendo. O Poder Constituinte e suas características intrínsecas foram apreciadas, mesmo com a criação de um Fórum para estabelecimento de diretrizes para a elaboração e a participação do povo via redes sociais.

Ademais, o referendo, aqui vislumbrado também como veto popular, foi de grande significância para a atuação soberana do povo. Por estratégia ou não, o fato de o Presidente da República ter deixado ir à consulta popular as decisões referentes ao pagamento da dívida ao FMI, impulsionou a manifestação contra o conservadorismo parlamentar e deu força para a organização do Fórum para a Constituinte. Embora o questionamento do referendo tenha sido entendido como "abusivo" ou específico demais para ser levado ao povo, é preciso notar que ele foi de suma importância para o desenrolar dos eventos. De fato, embora se prime pela soberania do povo, o verdadeiro titular do poder - em detrimento do mercado ou do capital -, deve-se compreender o risco que se corre ao passar a ele o poder de decisão de questões específicas, abstratas e tão importantes (tendo em vista que decidiram "dar o calote").

O risco que se corre ao delegar ao povo o poder de decisão é o risco dele próprio se gerir. Se as leis evoluem como a sociedade o faz, é melhor que elas evoluam aos mandos de seu corpo político suplantando os mandos do capital. Deixar o povo por sua "conta e risco", não significa exatamente deixar que o homem seja o lobo do próprio homem, como disse Thomas Hobbes, mas que ele rechace as amarras impostas pelos governantes, daí o "risco" é que o homem se torne o lobo do capital. O legado deixado pelo caso Islandês, além das características técnicas observadas, é, sem dúvida, o da soberania popular.

\section{REFERÊNCIAS BIBLIOGRÁFICAS}

ANTUNES, Vanderlei Lemos. O Conceito de Soberania em JeanJacques Rousseau. Controvérsia. v.2, n.1, p 70-77, 2006. Disponível em: <file:///C:/Users/Laura\%20Araújo/Downloads/7091-21538-1PB.pdf> Acesso em: 13 set. 2016. 
AZAMBUJA, Darcy; CARRASCO, Alexandre de Oliveira Torres. Teoria Geral do Estado. 2. ed. São Paulo: Globo, 2008.

BITTAR, Eduardo C. B. Metodologia da Pesquisa Jurídica: teoria e prática da monografia para os cursos de Direito. 13. ed. São Paulo: Saraiva, 2015.

BONAVIDES, Paulo. Curso de Direito Constitucional. 10 ed. rev, atual e ampl. São Paulo: Malheiros Editores, 2000.

. Ciência Política. 10. ed. São Paulo: Malheiros Editores, 2000.

BOTTOMORE, Tom. Dicionário do Pensamento Marxista. Rio de Janeiro: Jorge Zahar Editor Ltda., 2013. 705p. Disponível em: $<$ http://sociologial.dominiotemporario.com/doc/DICIONARIO_D O_PENSAMENTO_MARXISTA_TOM_BOTTOMORE.pdf > Acesso em: 19 set. 2016.

CARTA, Gianni. Felicidade por linhas tortas. 2015. Revista Carta Capita Online. Disponível em: <http://www.cartacapital.com.br/revista/841/a-felicidade-porlinhas-tortas-5300.html>. Acesso em: 10 abr. 2016.

DALLARI, Dalmo de Abreu. Elementos de Teoria Geral do Estado. 27. ed. São Paulo: Saraiva, 2007.

GARCIA, Alexandre Navarro. Democracia semidireta: Referendo, plebiscito, iniciativa popular e legislação participativa. Disponível em:

https://www2.senado.leg.br/bdsf/bitstream/handle/id/417/R166-

01.pdf?sequence=4. Acesso em: 10, nov. 2016.

LENZA, Pedro. Direito Constitucional Esquematizado. 18. ed. rev., atual e ampl. São Paulo: Saraiva, 2014.

MOTA, Leonardo de Araújo e. Capitalismo contemporâneo, desigualdades sociais e a crise de 2008. Revista Brasileira de Desenvolvimento Regional, Blumenau, v. 1, n. 1, p. 051-064, mar. Disponível

em: <http://proxy.furb.br/ojs/index.php/rbdr/article/view/3647>. Acesso em: 12 jul. 2016.

PACHECO, T. C. S. Análise comparativa entre as crises financeiras de 1929 e 2008: um arcabouço pós-keynesiano. (Monografia). Universidade Federal de Santa Catarina, Centro Socio-Econômico. Disponível em: <http://cnm.ufsc.br/files/2014/01/Monografia-daThaisa-Carla.pdf >. Acesso em: 22 abr. 2016.

PALSSON, G.; DURREMBERGER, E. P. Gambling Debt: Iceland's rise and fall in the global economy. Boulder: University Press of 
Colorado, 2014. Disponível em: <http://www.upcolorado.com/excerpts/9781607323358.pdf >. Acesso em: 07 jul. 2016.

SALLES, João Moreira. Manifestações derrubaram governo e prenderam banqueiros no início da crise. Revista Caros Amigos Online. Disponível em: http://www.carosamigos.com.br/index.php/artigos-e-debates/3262islandia-do-ardor-revolucionario-a-descrenca. Acesso em: $27 \mathrm{jul}$. 2016.

A ilha-laboratório. Revista Piauí, 22 março 2012. Disponível em: <http://piaui.folha.uol.com.br/materia/a-ilha-laboratorio/>. Acesso em: 20 ago. 2016.

SERENATO, Maurício Wosniaki. Evento, poder constituinte e democracia: uma análise a partir do caso islandês. Monografia graduação, UFPR, $2015 . \quad$ Disponível em: http://acervodigital.ufpr.br/handle/1884/42206. Acesso em: 07 jul. 2016.

Islândia: insurgência da democracia. Disponível em: http://assessoriajuridicapopular.blogspot.com.br/2015/04/islandiainsurgencia-da-democracia.html. Acesso em: 12 jul. 2016.

THOMAZ, Paula. A Islândia prepara nova constituição. Via Facebook. Revista Carta Capital Online, 7 de julho de 2011. Disponível em: $<$ http//www.cartacapital.com.br/internacional/a-islandia-preparanova-constituicao-via-facebook> Acesso em: 07 jul. 2016. 